\title{
Distinct mechanistic activity profile of pralatrexate in comparison to other antifolates in in vitro and in vivo models of human cancers
}

\author{
E. Izbicka $\cdot$ A. Diaz $\cdot$ R. Streeper $\cdot$ M. Wick $\cdot$ \\ D. Campos $\cdot$ R. Steffen $\cdot$ M. Saunders
}

Received: 22 July 2008 / Accepted: 26 December 2008 / Published online: 17 February 2009

(C) The Author(s) 2009. This article is published with open access at Springerlink.com

\begin{abstract}
Purpose This study evaluated mechanistic differences of pralatrexate, methotrexate, and pemetrexed.

Methods Inhibition of dihydrofolate reductase (DHFR) was quantified using recombinant human DHFR. Cellular uptake and folylpolyglutamate synthetase (FPGS) activity were determined using radiolabeled pralatrexate, methotrexate, and pemetrexed in NCI-H460 non-small cell lung cancer (NSCLC) cells. The tumor growth inhibition (TGI) was assessed using MV522 and NCI-H460 human NSCLC xenografts.

Results Apparent $K_{i}$ values for DHFR inhibition were 45, 26 , and $>200 \mathrm{nM}$ for pralatrexate, methotrexate, and pemetrexed, respectively. A significantly greater percentage of radiolabeled pralatrexate entered the cells and was polyglutamylatated relative to methotrexate or pemetrexed. In vivo, pralatrexate showed superior anti-tumor activity in

Preliminary reports of these studies were presented at the following meetings: Izbicka E, Diaz A, Campos D, Wick M, Steffen R, Saunders M (2007) Differential activity and potential mechanism of action of pralatrexate (PDX), methotrexate and pemetrexed (Alimta) in human cancer models in vivo and in vitro. Proc AACR-NCI-EORTC International Conference 108:A135, San Francisco, CA, October 2007.
\end{abstract}

Campos DR, Diaz A, Wick M, Steffen R, Saunders M, Izbicka E (2007) Distinct activity of pralatrexate in human cancer models in vivo and in vitro. Proc AACR Centennial Conference 49:B15, Singapore, November 4-9, 2007.

E. Izbicka · A. Diaz $\cdot$ R. Streeper · M. Wick ·

D. Campos

CTRC IDD, San Antonio, TX, USA

R. Steffen $\cdot$ M. Saunders $(\varangle)$

Allos Therapeutics, Inc., Westminster, CO, USA

e-mail: msaunders@allos.com both NSCLC models, with more effective dose-dependent TGI in the more rapidly growing NCI-H460 xenografts.

Conclusions Pralatrexate demonstrated a distinct mechanistic and anti-tumor activity profile relative to methotrexate and pemetrexed. Pralatrexate exhibited enhanced cellular uptake and increased polyglutamylation, which correlated with increased TGI in NSCLC xenograft models.

Keywords Pralatrexate - Antifolates · Polyglutamylation · Non-small cell lung cancer $\cdot$ Xenograft .

Dihydrofolate reductase (DHFR)

\section{Introduction}

Folate plays a key role in the one-carbon metabolic processes essential for deoxyribonucleic acid (DNA) replication. Antifolates are divalent anions which cross the cell membrane predominantly via the reduced folate carrier (RFC-1). RFC-1 is an oncofetoprotein found predominantly in the membranes of fetal and tumor cells [1]. Upon entry in the cell, antifolates are polyglutamylated by folylpolyglutamate synthetase (FPGS), and the polyglutamylated products tend to be retained within the cell. Polyglutamylation is a time- and concentration-dependent process that occurs in tumor cells and to a lesser extent in normal tissues. The longer intracellular half-life of these polyglutamylated conjugates extends product action in malignant cells through more effective dihydrofolate reductase (DHFR) inhibition [2, 3]. Because the intracellular concentration of antifolates is critical for their pharmacological activity, polyglutamylation is a key determinant of antifolate-mediated cytotoxicity [4].

Methotrexate was designed nearly 60 years ago and functions to block the activity of DHFR. Methotrexate is 
approved for use in the treatment of gestational choriocarcinoma, chorioadenoma destruens and hydatidiform mole. In acute lymphocytic leukemia, methotrexate is approved for the prophylaxis of meningeal leukemia and is used in maintenance therapy in combination with other chemotherapeutic agents. Methotrexate is used alone or in combination with other anticancer agents in the treatment of breast cancer, head and neck cancer, bladder cancer, advanced mycosis fungoides, and lung cancer, particularly squamous cell and small cell types. Methotrexate is also used in combination with other chemotherapeutic agents in the treatment of advanced stage non-Hodgkin's lymphomas. More recently investigated antifolates include raltitrexed $\left(\right.$ Tomudex $\left.^{\circledR}\right)$ and pemetrexed $\left(\right.$ Alimta $^{\circledR}$ ) which target thymidylate synthase (TS) and glycinamide ribonucleotide formyl transferase (GARFT). Alimta ${ }^{\circledR}$ is approved for the treatment of nonsmall cell lung cancer (NSCLC) and malignant pleural mesothelioma. Methotrexate has also been used extensively for treatment of certain autoimmune disorders, primarily rheumatoid arthritis [5-7].

Pralatrexate [PDX (RS)-10-propargyl-10-deazaaminopterin], is a 10-deazaaminopterin analog of methotrexate, and is a small-molecule inhibitor of DHFR (Fig. 1). Pralatrexate differs from methotrexate at position 10 where a carbon with a propargyl side chain is substituted for the nitrogen with a methyl substituent. Pralatrexate was rationally designed for improved cellular transport via RFC-1, and to have greater intracellular drug retention through the enhanced formation of polyglutamylated conjugates [2,3]. The relative difference in polyglutamate formation in normal versus malignant cells may account for the enhanced pharmacodynamic activity of pralatrexate. Pralatrexate is thought to exert its pharmacological effect primarily through inhibition of DHFR, having an $\mathrm{IC}_{50}$ in the picomolar range [8].

This study investigated the potential mechanistic differences between pralatrexate and other antifolates, specifically methotrexate and pemetrexed. Despite being introduced over 40 years ago, methotrexate is still used today in the treatment of several tumor types; however, few methotrexate analogues have been developed. In comparison to methotrexate, pralatrexate has demonstrated superior in vitro and in vivo anti-tumor activity in breast and lung cancer cell lines and in xenograft models of lymphoma [9, 10], human mammary carcinoma, and NSCLC [8]. Pralatrexate has been studied in three completed [11-13] and two ongoing clinical trials in NSCLC, and one completed study in mesothelioma [14]. In a Phase 2 study in NSCLC, the median time to progression of disease for patients who achieved stable disease and for those with a partial response (PR) was $\geq 10.5$ months. The median duration of survival was 13 months [13]. Furthermore, four clinical trials are ongoing in lymphoma. Preliminary data from one of the<smiles>C#CCC(Cc1cnc2nc(N)nc(N)c2n1)c1ccc(C(=O)N[C@@H](CCC(=O)O)C(=O)O)cc1</smiles>

Pralatrexate (PDX)<smiles>CN(Cc1cnc2nc(N)nc(N)c2n1)c1ccc(C(=O)N[C@@H](CCC(=O)O)C(=O)O)cc1</smiles>

Methotrexate (MTX)

Fig. 1 Pralatrexate and methotrexate structures

ongoing studies have shown responses in 14 of 26 (54\%) evaluable patients with $\mathrm{T}$ cell lymphoma, of which nine were complete responses (CR) [15].

\section{Materials and methods}

Reagents

Drugs used included $\left[{ }^{14} \mathrm{C}\right]$-pralatrexate, $28.4 \mathrm{mCi} / \mathrm{mmol}$, $4.58 \mu \mathrm{M}$ (Clauson-Kaas A/S, Farum, Denmark); $\left[{ }^{3} \mathrm{H}\right]-$ methotrexate, $49.6 \mathrm{Ci} / \mathrm{mmol}, 20.16 \mu \mathrm{M}$ (Moravek, Brea, $\mathrm{CA}$ ); $\left[{ }^{14} \mathrm{C}\right]$-pemetrexed, $51.7 \mathrm{mCi} / \mathrm{mmol}, 5.55 \mu \mathrm{M}$ (EaglePicher Pharmaceutical Services, LLC, Lenexa, KA); pralatrexate (Pharmaceutical Service, University of Iowa, Iowa City, IA), methotrexate (Sigma-Aldrich, St Louis, $\mathrm{MO}$ ), and pemetrexed (Eli Lilly, Indianapolis, IN).

In vitro studies

NCI-H460 human NSCLC cells obtained from the American Type Cell Collection, Manassas, VA, were propagated in vitro as described [16]. MV522 human metastatic human NSCLC cells were obtained from Dr. M.J. Kelner (University of California, San Diego) and propagated as described [16].

Enzyme activity assays

DHFR activity was determined using a spectrophotometric assay that measured the decrease of absorbance at $340 \mathrm{~nm}$ 
characteristic of dihydrofolate as it is reduced to tetrahydrofolate (THF) [17] using a DHFR activity assay kit (SigmaAldrich, St Louis, MO). The experiments were repeated at least twice. Apparent inhibition constants $\left(K_{i}\right.$ app) were determined using the INTERCEPT function (Microsoft Excel). To measure folylpolyglutamyl synthetase (FPGS) activity, we first optimized a conventional FPGS assay that used $\left[{ }^{14} \mathrm{C}\right]$-L-glutamic acid as a substrate for glutamylation [18] using archived tumor tissue xenografts from the in vivo study. Tumor tissue was processed as described [19]. FPGS activity was assayed at $37^{\circ} \mathrm{C}$ for $60 \mathrm{~min}$ in the presence of $1 \mathrm{mM} \mathrm{L}$-glutamate, $5 \mathrm{mM} \mathrm{MgATP}$, and $500 \mu \mathrm{M}$ aminopterin. The reaction was terminated by boiling the samples for $3 \mathrm{~min}$. The samples were chilled on ice and centrifuged. Product and substrates were separated after spotting onto PEI-cellulose thin-layer chromatography (TLC) sheets and chromatography, with $0.5 \%(\mathrm{w} / \mathrm{v}) \mathrm{NH}_{4} \mathrm{Cl}$ and $0.5 \%(\mathrm{v} / \mathrm{v}) \beta$-mercaptoethanol as eluents. TLC sheets were dried, individual lanes corresponding to discrete samples were cut out and further dissected into $0.5 \mathrm{~cm}$ sections. The sections were placed in Ready-Gel (Beckman, Fullerton, CA) and counted on a Beckman LS6500.

The above assay was modified to measure FPGS activity in NCI-H460 cells using radiolabeled drugs $\left[{ }^{14} \mathrm{C}\right.$-(pralatrexate or pemetrexed) or ${ }^{3} \mathrm{H}$-methotrexate] as the substrates for glutamylation. Briefly, NCI-H460 cells in the logarithmic growth phase were counted and plated in 12-well plates at a density of 500,000 cells per treatment group (all treatments in duplicate). The cells were incubated at $37^{\circ} \mathrm{C}$ for 15 or 60 min with (a) radiolabeled pralatrexate, methotrexate, or pemetrexed at $2 \mu \mathrm{M}$ final concentration each [specific activity of radiolabeled drugs was $56 \mu \mathrm{Ci} / \mathrm{mL}$ (pralatrexate), $95 \mu \mathrm{Ci} / \mathrm{mL}$ (methotrexate), and $103 \mu \mathrm{Ci} / \mathrm{mL}$ (pemetrexed)], (b) radiolabeled pralatrexate, methotrexate, or pemetrexed at $2 \mu \mathrm{M}$ final concentration each plus $1 \mathrm{mM}$ (500-fold molar excess) of the unlabeled respective drugs, or (c) vehicle. Following the incubation, the cell pellets were washed twice with ice-cold HEPES-buffered saline, to remove free radiolabeled drugs that were not taken up by the cells. The cells were then resuspended in water and lysed by sonication on ice followed by centrifugation at $14,000 \mathrm{~g}$ for $15 \mathrm{~min}$. Product and substrates were separated by TLC and the incorporated radioactivity was measured by liquid scintillation counting (LSC) as described above.

\section{In vivo xenograft studies}

Female nude mice (nu/nu) between 5 and 6 weeks of age weighing approximately $20 \mathrm{~g}$ were obtained from Harlan Inc. (Madison, WI). Fragments of NCI-H460 or MV522 harvested from tumors grown subcutaneously (SC) in host animals were implanted SC by trocar into the right flank of the nu/nu mice. When the tumors had grown to approximately $100 \mathrm{~mm}^{3}$ in size, animals were paired by tumor size into treatment and control groups; each group contained nine mice. The antifolates were administered as single agents via intraperitoneal (IP) injection. Pralatrexate was dosed at 1 and $2 \mathrm{mg} / \mathrm{kg}$ [every day (QD) $\times 5$, for two cycles of 5 days each]. Other treatments included pemetrexed $(150 \mathrm{mg} / \mathrm{kg}$; QD $\times 5$, for two cycles) and methotrexate $(1$ and $2 \mathrm{mg} / \mathrm{kg}$; QD $\times 5$, for two cycles). Equivalent doses of the two antifolates were chosen as there were no previous data available in this murine model. Significant endpoints included mean tumor growth inhibition (TGI), weight loss, and treatment toxicity determined as described [19]. Principles of laboratory animal care per NIH publication 85-23 (revised 1985) were followed in all animal experiments.

\section{Results}

To evaluate the relative potency of the three drugs as DHFR inhibitors, the inhibitory activity of pralatrexate in a cell-free system against recombinant human DHFR was compared to the inhibitory activities of methotrexate and pemetrexed. Initial velocities of the DHFR enzymatic reaction were measured in the presence and absence of pralatrexate. The results showed clear concentration-dependent inhibition of activity by pralatrexate (Fig. 2a). Similar patterns of concentration-dependent inhibition were observed with methotrexate and pemetrexed (data not shown). Plots of the initial velocities were used to calculate apparent inhibition constants $\left(K_{i}\right.$ app) of DHFR inhibition by the antifolates. Respective $K_{i}$ app values were $45 \mathrm{nM}$ and $26 \mathrm{nM}$ for pralatrexate (Fig. 2b) and methotrexate (Fig. 2c). Pemetrexed was a weak inhibitor of DHFR relative to pralatrexate and methotrexate; only $40 \%$ relative inhibition was observed at $200 \mathrm{nM}$ pemetrexed (Fig. 2d).

The biological activity of many clinically useful antifolates is directly related to the intracellular concentration of polyglutamylated species of the drug produced by the action of FPGS [20]. Since pralatrexate, methotrexate, and pemetrexed are substrates for FPGS, we hypothesized that their biological activity may be related to the extent of polyglutamylation and the resultant increase in concentration of the polyglutamylated derivatives in cancer cells.

In our preliminary experiments we have demonstrated using a standard FPGS assay [18] that non-polyglutamylated drugs had distinctly different TLC mobilities relative to the polyglutamylated derivatives (data not shown). Based on these results, which were consistent with an earlier report [18], we anticipated that the radiolabeled polyglutamylated products could be separated from the unreacted ${ }^{14} \mathrm{C}$-labeled glutamate (retention factor $R_{f}=0.6$ ) by standard TLC methods. 

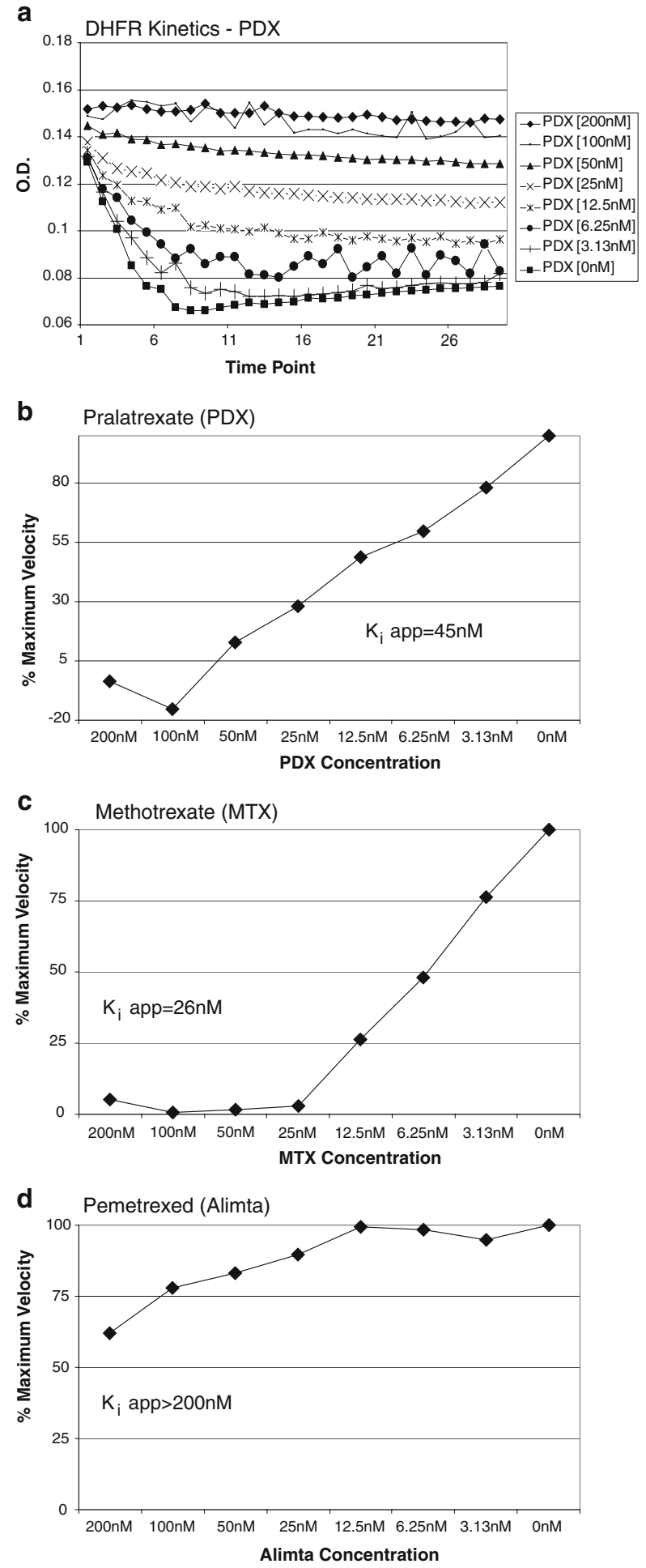

Fig. 2 Inhibition of DHFR activity by pralatrexate in a cell-free system. a Concentration dependence of DHFR activity. b-d Estimation of $K_{i}$ app for DHFR inhibition by pralatrexate, methotrexate, and pemetrexed, respectively

To test this hypothesis, we modified a conventional FPGS activity assay, which employed radiolabeled L-glutamate and unlabeled antifolates as substrates, and substituted them with unlabeled L-glutamate and radiolabeled antifolates instead. Given that the radiolabeled polyglutamylated products would have different mobilities compared to that of non-glutamylated substrates, these species could be resolved using TLC. Our modified in vitro assay used radiolabeled pralatrexate, methotrexate, and pemetrexed and unlabeled L-glutamate to compare the short-term uptake of radiolabeled antifolates in NCI-H460 cells. The drugs were incubated with the cells for either 15 or $60 \mathrm{~min}$ in two regimens; (a) radiolabeled drug alone, or (b) radiolabeled agent plus 500-fold molar excess of the unlabeled drugs.

As illustrated in Fig. 3, the radiolabel was detectable in species of low mobility $\left(R_{f}<0.2\right.$; TLC sections 1 and 2 corresponding to free drugs) and high mobility $\left(R_{f}>0.5\right.$; TLC sections 7-12; presumably the high mobility species were polyglutamylated drug species). The background radioactivity was similar for all drugs. Given that the same total number of cells was used for each drug treatment, the results are normalized per total protein content. The higher background radioactivity observed for methotrexate was due to a radio-impurity in the preparation of the labeled compound. The total uptake of radiolabeled drugs, which was measured at 15 and $60 \mathrm{~min}$, was similar at both times for methotrexate and decreased over time for pemetrexed. Greater radiolabel uptake was only observed with pralatrexate at $60 \mathrm{~min}$. A significantly smaller molar fraction of radiolabeled methotrexate and pemetrexed entered the cells relative to the absorbed molar fraction of pralatrexate. Radiolabeled species (polyglutamylated pralatrexate) having greater $R_{f}$ values than pralatrexate alone in a cellfree system $\left(R_{f}>0.5\right)$ appeared in a time-dependent manner in pralatrexate-treated cell extracts. Pemetrexed was polyglutamylatated to a lesser extent than was pralatrexate. No polyglutamylated forms of methotrexate could be observed. Only in the case of pralatrexate was a drug-specific increase in polyglutamylated species observed because only for pralatrexate was the increase in polyglutamylated species significantly mitigated $(>84 \%)$ by the addition of excess unlabeled drug. Notably, because the specific radioactivity of pralatrexate was approximately twofold lower than that of methotrexate or pralatrexate, these data are likely to underestimate the extent of polyglutamylation by pralatrexate.

To compare relative potencies and antitumor activities of the antifolates, their in vivo activity was measured in a pilot study using two human NSCLC models, MV522 and NCIH460, with TGI as the primary efficacy endpoint (Fig. 4a). In MV522, high-dose pralatrexate treatment resulted in treatment-related toxicity, as determined by significant weight loss in some animals prior to death; however, remaining mice regained all lost weight by Day 35 (Fig. 4b). TGI (38\%) was observed in the $2 \mathrm{mg} / \mathrm{kg}$ pralatrexate-treated group, indicating activity in this model, although pralatrexate was not considered active in this model according to NCI standards (TGI $>58 \%$ ). Pralatrexate was 

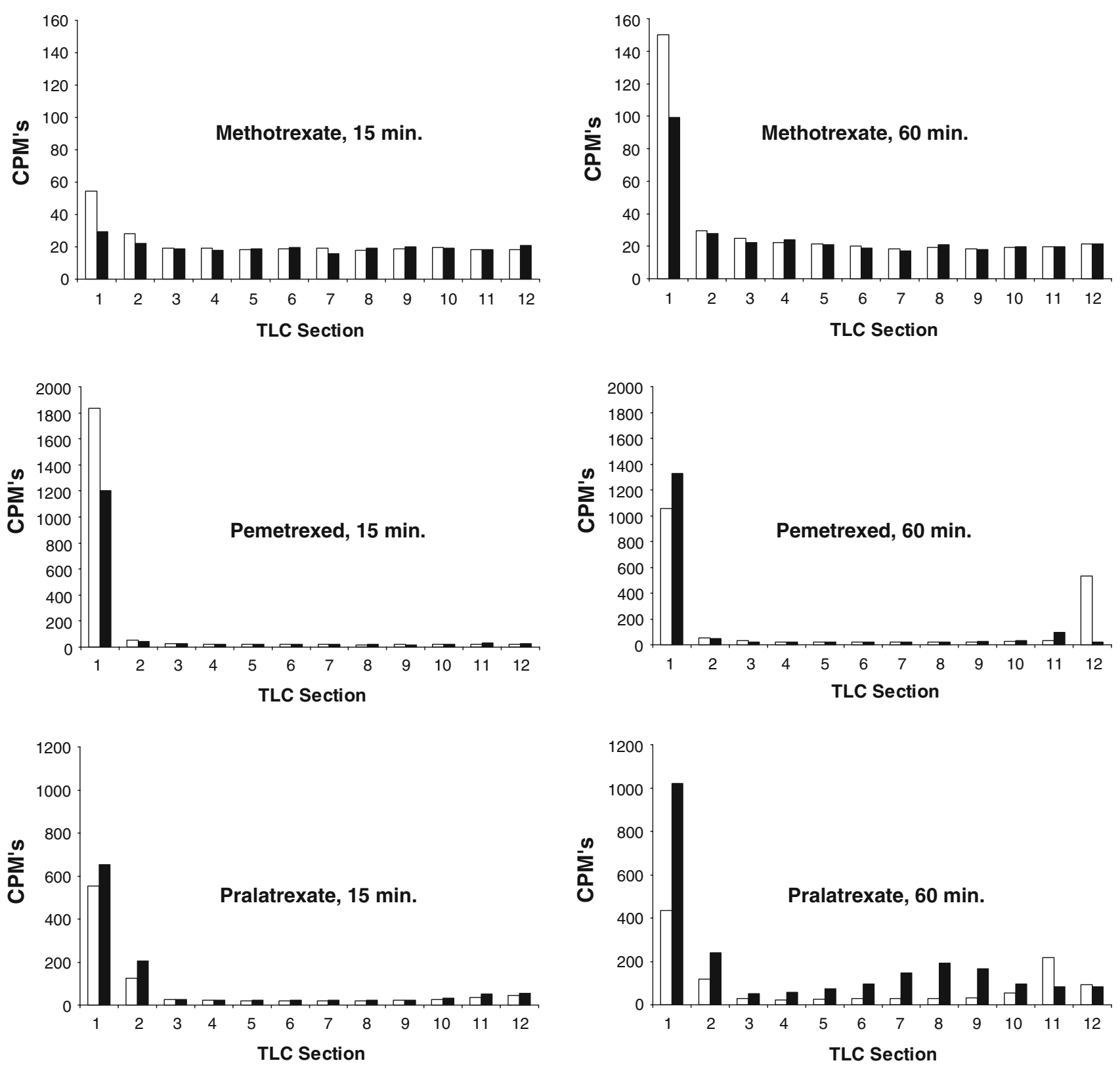

Fig. 3 A short-term uptake of radiolabeled antifolates in NCI-H460 cells Drugs were dosed for 15 or 60 min. White bars cells incubated with radiolabeled drug only, black bars cells incubated with radiolabeled drug plus excess unlabeled drug

superior to methotrexate and pemetrexed at the evaluated doses in this model. However, the TGI value calculated for pralatrexate was based on results from only four animals, limiting more concrete comparison of the groups. Overall, the results from the remaining animals demonstrated increased antitumor activity with pralatrexate in the MV522 model compared to methotrexate and pemetrexed.

In NCI-H460 (Fig. 4b), single-agent pralatrexate treatment resulted in dose-dependent weight loss, which the animals had not recovered from by study completion. Aggressive tumor growth prevented further analysis of possible weight recovery in this group. TGI was reported in groups dosed with $1(34 \%)$ or $2(52 \%) \mathrm{mg} / \mathrm{kg}$ pralatrexate (Fig. $4 \mathrm{a})$. While neither dose group met the NCI criteria for an active agent (TGI $>58 \%$ ), TGI in the $2 \mathrm{mg} / \mathrm{kg}$ group reached statistical significance $(P<0.05)$ versus control, indicating activity in this model. In a direct comparison, pralatrexate was superior to either dose of methotrexate ( 1 and $2 \mathrm{mg} / \mathrm{kg}$ ), and pemetrexed $(150 \mathrm{mg} / \mathrm{kg})$ was inactive in this model. Overall, pralatrexate demonstrated dose-dependent antitumor activity in the NCI-H460 model and demonstrated greater activity than methotrexate at the same dose-treatment schedule. 
a

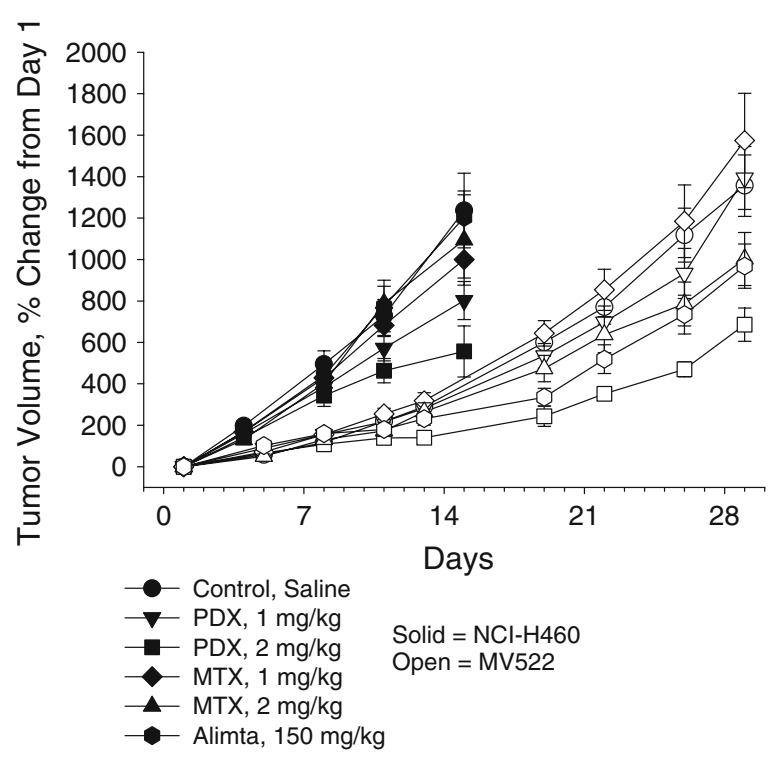

b

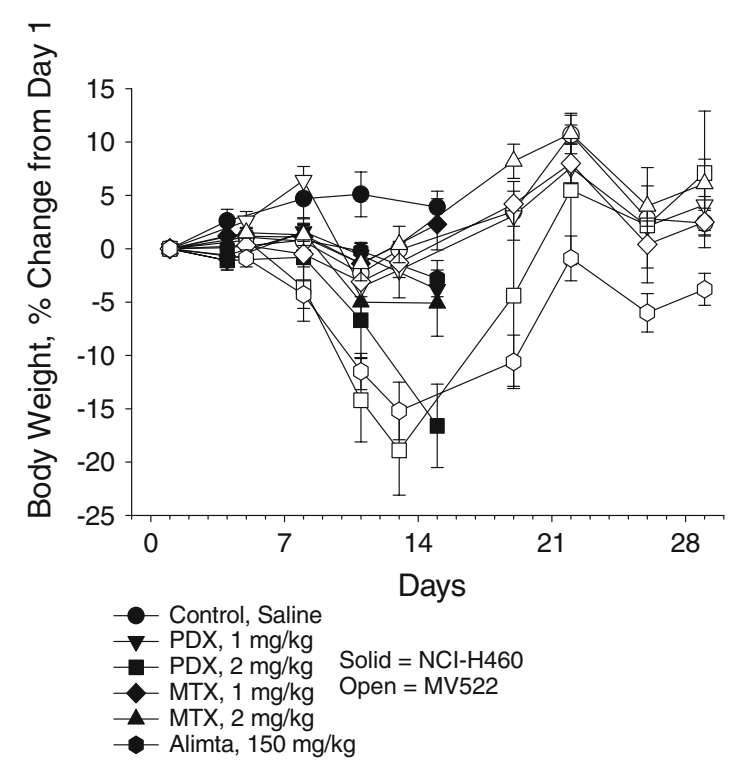

Fig. 4 Differential activity of the antifolates on tumor volume and body weight in NCI-H460 and MV522 human tumor xenografts. a Percent change in tumor volume. b Percent change in total body weight. $P D X$ pralatrexate, MTX methotrexate, Alimta pemetrexed

\section{Discussion}

This study reports a head-to-head comparison of in vitro and in vivo activities of three antifolates: pralatrexate, methotrexate, and pemetrexed. A clear difference was demonstrated among the antifolates in regulation of enzymatic activity. Pralatrexate demonstrated a unique activity profile relative to methotrexate and pemetrexed. The in vitro mechanistic differences were established through enhanced cellular uptake and intracellular polyglutamylation of pralatrexate, correlating with more effective TGI by pralatrexate in two NSCLC xenograft models in vivo compared to methotrexate or pemetrexed. Unlike pralatrexate, the activities of methotrexate and pemetrexed were found to be model-dependent. Interestingly, however, a greater degree of dose-dependent effect of pralatrexate on TGI was observed in the more rapidly growing NCI-H460 xenograft model.

The observation of enhanced polyglutamylation of pralatrexate in human cancer cells suggests that pralatrexate may overcome some of the limitations associated with antifolate resistance, which represents a major challenge in cancer chemotherapy with agents of this class. The most common mechanisms of antifolate resistance are associated with qualitative and/or quantitative alterations in influx or efflux transport of antifolates [4], and in some instances, mutations in folate-dependent enzymes [21, 22]. The predominant mechanism of resistance to many antifolates including methotrexate and pemetrexed, is impaired polyglutamylation due to significantly decreased FPGS activity. Multifunctional mechanisms of resistance in cancer cells have a differential impact on cellular folate homeostasis including decreased polyglutamylation and transport defects that lead to folate depletion [23].

The mechanisms of antifolate sensitivity are almost certainly more complex than has heretofore been appreciated. The effects of FPGS modulation on the chemosensitivity of human cancer cells to methotrexate depend not only on polyglutamylation of a specific target intracellular folate cofactor or methotrexate, but also on total intracellular folate pools and polyglutamylation of other intracellular substrates. It remains to be determined whether FPGS modulation is a relevant index of chemosensitivity of cancer cells to methotrexate [24]. Pralatrexate differs from other antifolates both structurally and mechanistically, which has been demonstrated in this study to translate into differences in anti-tumor activity.

This study confirms previous observations of enhanced intracellular drug retention and formation of polyglutamylated metabolites of pralatrexate relative to other antifolates $[2,3]$. These polyglutamylated metabolites have a prolonged intracellular half-life and allow for extended drug action in malignant cells and more effective DHFR inhibition by the polyglutamylated forms [2, 3]. The relative differences in observed polyglutamate adduct formation in normal versus malignant cells may account for the enhanced pharmacodynamic activity of pralatrexate.

Open Access This article is distributed under the terms of the Creative Commons Attribution Noncommercial License which permits any noncommercial use, distribution, and reproduction in any medium, provided the original author(s) and source are credited. 


\section{References}

1. O'Connor OA, Hamlin PA, Portlock C, Moskowitz CH, Noy A, Straus DJ, Macgregor-Cortelli B, Neylon E, Sarasohn D, Dumetrescu O et al (2007) Pralatrexate, a novel class of antifol with high affinity for the reduced folate carrier-type 1 , produces marked complete and durable remissions in a diversity of chemotherapy refractory cases of $\mathrm{T}$-cell lymphoma. $\mathrm{Br} \mathrm{J}$ Haematol 139(3):425-428

2. Sirotnak FM, DeGraw JI, Moccio DM, Samuels LL, Goutas LJ (1984) New folate analogs of the 10-deaza-aminopterin series. Basis for structural design and biochemical and pharmacologic properties. Cancer Chemother Pharmacol 12(1):18-25

3. Sirotnak FM, Schmid FA, Samuels LL, DeGraw JI (1987) 10-Ethyl-10-deaza-aminopterin: structural design and biochemical, pharmacologic, and antitumor properties. NCI Monogr (5):127-131

4. Assaraf YG (2007) Molecular basis of antifolate resistance. Cancer Metastasis Rev 26(1):153-181

5. Chan ES, Cronstein BN (2002) Molecular action of methotrexate in inflammatory diseases. Arthritis Res 4(4):266-273

6. Emery P, Breedveld FC, Hall S, Durez P, Chang DJ, Robertson D, Singh A, Pedersen RD, Koenig AS, Freundlich B (2008) Comparison of methotrexate monotherapy with a combination of methotrexate and etanercept in active, early, moderate to severe rheumatoid arthritis (COMET): a randomised, double-blind, parallel treatment trial. Lancet 372(9636):375-382

7. Wessels JA, Huizinga TW, Guchelaar HJ (2008) Recent insights in the pharmacological actions of methotrexate in the treatment of rheumatoid arthritis. Rheumatology (Oxford) 47(3):249-255

8. Sirotnak FM, DeGraw JI, Colwell WT, Piper JR (1998) A new analogue of 10-deazaaminopterin with markedly enhanced curative effects against human tumor xenografts in mice. Cancer Chemother Pharmacol 42(4):313-318

9. Wang ES, O'Connor O, She Y, Zelenetz AD, Sirotnak FM, Moore MA (2003) Activity of a novel anti-folate (PDX, 10-propargyl 10deazaaminopterin) against human lymphoma is superior to methotrexate and correlates with tumor RFC-1 gene expression. Leuk Lymphoma 44(6):1027-1035

10. Toner LE, Vrhovac R, Smith EA, Gardner J, Heaney M, Gonen M, Teruya-Feldstein J, Sirotnak F, O'Connor OA (2006) The schedule-dependent effects of the novel antifolate pralatrexate and gemcitabine are superior to methotrexate and cytarabine in models of human non-Hodgkin's lymphoma. Clin Cancer Res 12(3 Pt 1):924-932

11. Krug LM, Ng KK, Kris MG, Miller VA, Tong W, Heelan RT, Leon L, Leung D, Kelly J, Grant SC et al (2000) Phase I and pharmacokinetic study of 10-propargyl-10-deazaaminopterin, a new antifolate. Clin Cancer Res 6(9):3493-3498

12. Azzoli CG, Krug LM, Gomez J, Miller VA, Kris MG, Ginsberg MS, Henry R, Jones J, Tyson L, Dunne M et al (2007) A phase 1 study of pralatrexate in combination with paclitaxel or docetaxel in patients with advanced solid tumors. Clin Cancer Res 13(9):2692-2698

13. Krug LM, Azzoli CG, Kris MG, Miller VA, Khokhar NZ, Tong W, Ginsberg MS, Venkatraman E, Tyson L, Pizzo B et al (2003)
10-Propargyl-10-deazaaminopterin: an antifolate with activity in patients with previously treated non-small cell lung cancer. Clin Cancer Res 9(6):2072-2078

14. Krug LM, Heelan RT, Kris MG, Venkatraman E, Sirotnak FM (2007) Phase II trial of pralatrexate (10-propargyl-10-deazaaminopterin, PDX) in patients with unresectable malignant pleural mesothelioma. J Thorac Oncol 2(4):317-320

15. O'Connor OA, Hamlin PA, Portlock C, Moskowitz CH, Noy A, Straus DJ, Dumetrescu O, Sarasohn D, Neylon E, Hamelers R et al (2007) A Phase '2-1-2' study of two different doses and schedules of pralatrexate, a high affinity substrate for the reduced folate carrier (RFC-1), in patients with relapsed or refractory lymphoma reveals marked activity in T-cell malignancies (abstract C85). AACR-NCI-EORTC international conference molecular targets and cancer therapeutics, $\mathrm{p} 283$

16. Izbicka E, Campos D, Carrizales G, Patnaik A (2005) Biomarkers of anticancer activity of R115777 (Tipifarnib, Zarnestra) in human breast cancer models in vitro. Anticancer Res 25(5):3215-3223

17. Delcamp TJ, Susten SS, Blankenship DT, Freisheim JH (1983) Purification and characterization of dihydrofolate reductase from methotrexate-resistant human lymphoblastoid cells. Biochemistry 22(3):633-639

18. van Triest B, Pinedo HM, van Hensbergen Y, Smid K, Telleman F, Schoenmakers PS, van der Wilt CL, van Laar JA, Noordhuis P, Jansen G et al (1999) Thymidylate synthase level as the main predictive parameter for sensitivity to 5-fluorouracil, but not for folate-based thymidylate synthase inhibitors, in 13 nonselected colon cancer cell lines. Clin Cancer Res 5(3):643-654

19. Izbicka E, Campos D, Marty J, Carrizales G, Mangold G, Tolcher A (2006) Molecular determinants of differential sensitivity to docetaxel and paclitaxel in human pediatric cancer models. Anticancer Res 26(3A): 1983-1988

20. Gangjee A, Jain HD, Kurup S (2007) Recent advances in classical and non-classical antifolates as antitumor and antiopportunistic infection agents: part I. Anticancer Agents Med Chem 7(5):524 542

21. Leclerc GJ, York TA, Hsieh-Kinser T, Barredo JC (2007) Molecular basis for decreased folylpoly-gamma-glutamate synthetase expression in a methotrexate resistant CCRF-CEM mutant cell line. Leuk Res 31(3):293-299

22. Liani E, Rothem L, Bunni MA, Smith CA, Jansen G, Assaraf YG (2003) Loss of folylpoly-gamma-glutamate synthetase activity is a dominant mechanism of resistance to polyglutamylationdependent novel antifolates in multiple human leukemia sublines. Int J Cancer 103(5):587-599

23. Mauritz R, Peters GJ, Priest DG, Assaraf YG, Drori S, Kathmann I, Noordhuis P, Bunni MA, Rosowsky A, Schornagel JH et al (2002) Multiple mechanisms of resistance to methotrexate and novel antifolates in human CCRF-CEM leukemia cells and their implications for folate homeostasis. Biochem Pharmacol 63(2): 105-115

24. Cho RC, Cole PD, Sohn KJ, Gaisano G, Croxford R, Kamen BA, Kim YI (2007) Effects of folate and folylpolyglutamyl synthase modulation on chemosensitivity of breast cancer cells. Mol Cancer Ther 6(11):2909-2920 